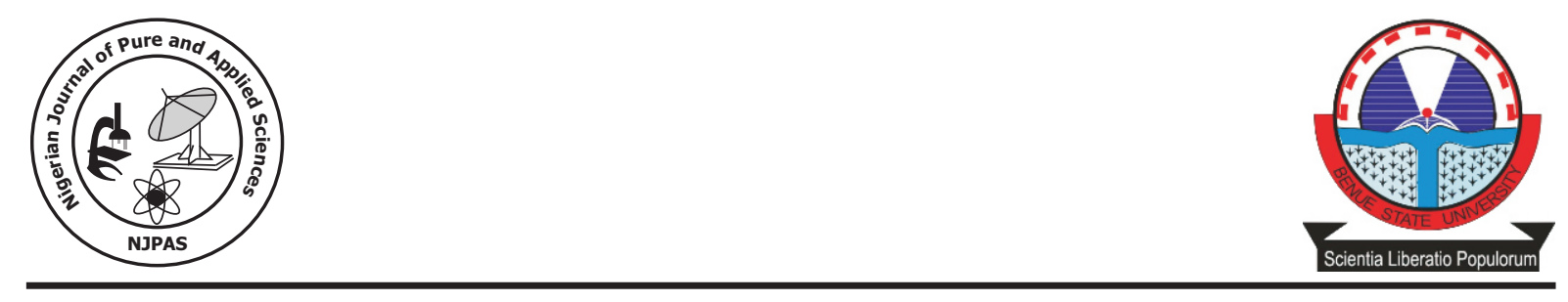

\title{
Minimizing the Cost of Transporting Goods Produced in an Integrated Foods Company.
}

\author{
Kembe, M. M., ${ }^{1}$ Kimbir, A. R., ${ }^{2}$ and Ogbuagu, E. M. ${ }^{2}$ \\ 1. Department of Mathematics and Computer Science, Benue State University, Makurdi \\ 2. Department of Mathematics and Computer Science, University of Agriculture, Makurdi
}

\begin{abstract}
The transportation cost of goods in any company or organization is a pivotal element in determining the total cost of production and also the net profit that will be made. The main aim of this study is to minimize the cost of transporting goods produced at Grand Cereals Limited, Jos, which is reducing the cost of transportation from the major plant where the goods are produced to the various distribution centers. Data was collected on the average quantity of Brabusco Maize Flour (10 kg), Grand Pure Soya Oil (10 litres), Vita Chicks Pelletized Feeds $(25 \mathrm{~kg}, 9 \mathrm{~mm}$ ) and Royal Layer Concentrate Feeds $(25 \mathrm{~kg})$ produced monthly at the Jos plant, the average quantity demanded by major distributors across the country (Yola, Dutse, Minna, Abuja, Aba, Onitsha, Calabar and lkeja) and the cost of transporting them. The Vogel's Approximation Method of the TORA Optimization System Software was used in solving the formulated transportation problem, and an optimal solution of N3,427,821.00 was obtained, which reduced the monthly transportation cost by N332,179.00. Furthermore, sensitivity analysis was carried out on the parameters after the optimal solution was obtained, which shows that the optimal solution is strongly sensitive to changes in the problem parameters. It was concluded that this work has reduced the transportation cost of the company and therefore recommended to the management of the company for adoption in planning their transportation schedule at a minimum cost.
\end{abstract}

Keywords: Transportation Schedule, TORA, Sensitivity Analysis, Feasible Solution and Optimal Solution

\section{Introduction}

Transportation is very important and essential to the existence of man. We all move from one location to another or move goods and services from one location to another, thereby practicing transportation.

Transport costs are a monetary measure of what the transport seeker must pay to obtain transportation services. They come as fixed (infrastructure) and variable (operating) costs, depending on a variety of conditions related to geography, infrastructure, administrative barriers, energy, and on how passengers and freight are carried. Transport costs have significant impacts on the structure of economic activities as well as on international trade. Empirical evidence underlines that raising transport costs by $10 \%$ reduces trade volumes by more than $20 \%$ (Jonnson, 2008).

Grand Cereals Limited (GCL) is an integrated foods company located on a 16 acre site at km. 17, Zawan Roundabout, Bukuru, Jos South, Plateau State. The company has two other smaller production plants located in Gerawa, Kano State and Onitsha, Anambra State where they mostly crush and store raw materials. It produces household products such as edible oil, cereals, 
animal and fish feed.

The company is large and therefore produces a lot of goods ready to be shipped out on a daily basis. But they have not employed any scientific method of transporting their products to cut down cost, thereby making it more expensive.

This study therefore intends to minimize the cost of transporting the goods produced at Grand Cereals Limited by modeling it into a transportation problem and solving it using the Vogel's approximation method.

The main aim of this study is to obtain a minimized transportation cost for goods produced at Grand Cereals Limited, Jos such that the cost of transportation from the major plant where they are produced to the various distribution centers is minimized.

The specific objectives are to

I. Reduce the amount spent on transportation of goods from the major production plant to the distribution centers.

ii Carry out sensitivity analysis on the problem parameters and see how it affects the reduced cost that will be obtained.

\section{Methods}

This study will adopt the existing transportation model. The formulation of the transportation model employs double -subscripted variables of the form $X_{i j .}$. Thus, the general formulation of the transportation problem with $m$ sources and $n$ destinations, with the following notation;

$i=$ index for origins (supply points), $i=1,2,3$, ...m

$j=$ index for destination (demand points), $j=$ $1,2,3, \ldots, n$

$X_{i j}=$ number of units transported from origin $i$ to destination $j$

$d_{j}=$ demand in units at origin $j$.

is given by;

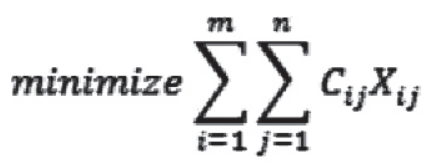

$$
\begin{aligned}
& \text { subject to } \sum_{j=1}^{n} X_{i j}=s_{i}, i=1,2, \ldots, m \text { (supply constraints) } \\
& \text { subject to } \sum_{i=1}^{m} c_{i j}=d_{j}, j=1,2, \ldots, n \text { (demand constraints) }
\end{aligned}
$$

$\boldsymbol{X}_{i j}>0, i=1,2, \ldots, m, j=1,2, \ldots, n$.

\section{Method of Finding Initial Basic Feasible Solution}

There are several methods of finding initial basic feasible solution of transportation problems. For the purpose of this study, we shall use the Vogel's Approximation Method, because it produces an Initial Basic Feasible Solution that is closest to the Optimal Solution. This has been proven from many literatures such as Asase (2011), Sharma (2010) and Sen et al., (2010) that it is the method that produces the best Initial Basic Feasible Solution out of all the available methods. In many cases, the Initial Basic Feasible Solution obtained by the Vogel's Approximation Method will be optimal.

\section{Sensitivity Analysis.}

Analyzing how the optimal value changes when the problem data is changed is called Sensitivity Analysis. It is carried out after the optimal solution has been obtained, to see how a change in the parameters can affect it. The Brute Force Method of Sensitivity Analysis was used in this work.

\section{Results}

This chapter contains the results of the analysis carried out on the data collected at Grand Cereals Limited, Jos, Plateau State. The company's products, namely Brabusco Maize flour (10kg), Grand Pure Soya Oil (10 litres), Vita Chicks Pelletised feeds ( $25 \mathrm{~kg} / 9 \mathrm{~mm})$ and Royal Layer Concentrate feeds $(25 \mathrm{~kg}$ ) will be used as our origins, since the company has only one production site, and the location of the major distributors namely Yola, Dutse, Minna, Abuja, Aba, Onitsha, Calabar and Ikeja will be used as the destinations. The data is summarized in the table below. 
Table 4: Summary of Data Collected (Balanced Transportation Problem)

\begin{tabular}{lccccccccc}
\hline YOL & DUT & MIN & ABJ & ABA & ONI & CAL & IKJ & DD & Available \\
\hline BRAB 23 & 23 & 23 & 23 & 53 & 53 & 53 & 60 & 0 & 1327 \\
SOYA 20 & 20 & 20 & 20 & 45 & 45 & 45 & 51 & 0 & 20614 \\
VCPF 58 & 58 & 58 & 58 & 133 & 133 & 133 & 150 & 0 & 46269 \\
RLCF 58 & 58 & 58 & 58 & 133 & 133 & 133 & 150 & 0 & 15433 \\
Demand & 18290 & 13077 & 12699 & 8488 & 1656 & 1703 & 3175 & 7496 & 17059 \\
\hline
\end{tabular}

YOL, DUT, MIN, ABJ, ABA, ONI, CAL and IKJ are the code names of the various locations of the major distributors, representing Yola, Dutse, Minna, Abuja, Aba, Onitsha, Calabar and Ikeja respectively. Also, BRAB, SOYA, VCPF and RLCF are the code names of the variety of goods, representing Brabusco Maize Flour, Grand Pure Soya Oil, Vita Chicks Pelletized and Royal Layer Concentrate Feeds respectively.

\section{The Vogel's Approximation Method}

The Vogel's Approximation Method was used to solve for an optimal solution and Figure 4.1 shows the solution iterations using the method and Table 4.3 below shows the model output summary.

\section{Statistical Software.}

The Windows-based TORA Optimization System Software was used in the course of this research work. The software was used to obtain the optimal solution of the transportation problem and also to obtain sensitivity analysis.

\begin{tabular}{|c|c|c|c|c|c|c|c|c|c|c|c|c|}
\hline & NAME & & $\begin{array}{l}\text { D1 } \\
\text { LAG } \\
\text { v1 = } \\
52.00\end{array}$ & $\begin{array}{l}\text { D2 } \\
\text { SKT } \\
\text { v2 = } \\
46.00\end{array}$ & $\begin{array}{l}\text { D3 } \\
\text { ILO } \\
\text { v3=21.00 }\end{array}$ & $\begin{array}{l}D 4 \\
A B J \\
v 4=41.00\end{array}$ & $\begin{array}{l}\text { D5 } \\
\text { OSHA } \\
\text { v5=24.00 }\end{array}$ & $\begin{array}{l}\text { D6 } \\
\text { KAN } \\
\text { v6=24.00 }\end{array}$ & $\begin{array}{l}\text { D7 } \\
\text { CAL } \\
v 7=58.00\end{array}$ & $\begin{array}{l}\text { D8 } \\
\text { YOL } \\
\text { v8=43.00 }\end{array}$ & $\begin{array}{l}\text { D9 } \\
\text { Dummy D } \\
\text { v9= } \\
12.00\end{array}$ & Supply \\
\hline S1 & BRAB & $u 1=0.00$ & $\begin{array}{l}23.00 \\
1327 \\
0.00\end{array}$ & $\begin{array}{l}23.00 \\
0.00\end{array}$ & $\begin{array}{l}23.00 \\
0.00\end{array}$ & $\begin{array}{l}23.00 \\
0.00\end{array}$ & $\begin{array}{l}53.00 \\
-5.00\end{array}$ & $\begin{array}{l}53.00 \\
-5.00\end{array}$ & $\begin{array}{l}53.00 \\
-5.00\end{array}$ & $\begin{array}{l}60.00 \\
-6.00\end{array}$ & $\begin{array}{l}0.00 \\
-35.00\end{array}$ & 1327 \\
\hline S2 & SOYA & $u 2=-3.00$ & $\begin{array}{l}20.00 \\
6584 \\
0.00 \\
\end{array}$ & $\begin{array}{l}20.00 \\
0.00 \\
\end{array}$ & $\begin{array}{l}20.00 \\
0.00 \\
\end{array}$ & $\begin{array}{l}20.00 \\
0.00\end{array}$ & $\begin{array}{l}45.00 \\
1656 \\
0.00 \\
\end{array}$ & $\begin{array}{l}45.00 \\
1703 \\
0.00 \\
\end{array}$ & $\begin{array}{l}45.00 \\
3175 \\
0.00 \\
\end{array}$ & $\begin{array}{l}51.00 \\
7496 \\
0.00 \\
\end{array}$ & $\begin{array}{l}0.00 \\
-38.00 \\
\end{array}$ & 20614 \\
\hline S3 & VCPF & $u 3=35.00$ & $\begin{array}{l}58.00 \\
1037 \\
9 \\
0.00\end{array}$ & $\begin{array}{l}58.00 \\
1307 \\
7 \\
0.00\end{array}$ & $\begin{array}{l}58.00 \\
5754 \\
0.00\end{array}$ & 58.00 & $\begin{array}{r}133.00 \\
-50.00\end{array}$ & 133.00 & 133.00 & 150.00 & $\begin{array}{l}0.00 \\
17059 \\
0.00\end{array}$ & 46269 \\
\hline S4 & RLCF & $u 4=35.00$ & $\begin{array}{l}58.00 \\
0.00\end{array}$ & $\begin{array}{l}58.00 \\
0.00\end{array}$ & $\begin{array}{l}58.00 \\
6945 \\
0.00\end{array}$ & $\begin{array}{l}58.00 \\
8488 \\
0.00\end{array}$ & $\begin{array}{l}133.00 \\
-50.00\end{array}$ & $\begin{array}{l}133.00 \\
-50.00\end{array}$ & $\begin{array}{l}133.00 \\
-50.00\end{array}$ & $\begin{array}{l}150.00 \\
-61.00\end{array}$ & $\begin{array}{l}0.00 \\
0.00\end{array}$ & 15433 \\
\hline & Demand & & 18290 & 13077 & 12699 & 8488 & 1656 & 1703 & 3175 & 7496 & 17059 & \\
\hline
\end{tabular}

Figure 1.0 Transportation Model - Tableau (Vogel's Method)

Iteration 1: (Optimal) ObjVal 3427821.00 
Table 1: Transportation Model Output Summary

\begin{tabular}{|c|c|c|c|c|c|c|}
\hline \multicolumn{7}{|c|}{ Objective Value (minimum cost) $=3427821.00$} \\
\hline From & & To & & Amt. Shipped & Obj. Coeff. & Obj. Contrib. \\
\hline S1: & BRAB & D1: & YOL & 1327 & 23.00 & 30521.00 \\
\hline S2: & SOYA & D1: & YOL & 6584 & 20.00 & 131680.00 \\
\hline S2 & SOYA & D5: & ABA & 1656 & 45.00 & 74520.00 \\
\hline S2: & SOYA & D6: & ONI & 1703 & 45.00 & 76635.00 \\
\hline S2: & SOYA & D7: & CAL & 3175 & 45.00 & 142875.00 \\
\hline S2: & SOYA & D8: & IKJ & 7496 & 51.00 & 382296.00 \\
\hline S3: & VCPF & D1: & YOL & 3434 & 58.00 & 199172.00 \\
\hline S3: & VCPF & D2: & DUT & 13077 & 58.00 & 758466.00 \\
\hline S3: & VCPF & D3: & MIN & 12699 & 58.00 & 736542.00 \\
\hline S3: & VCPF & D9: & DummyD & 17059 & 0.00 & 0.00 \\
\hline S4: & RLCF & D1: & YOL & 6945 & 58.00 & 402810.00 \\
\hline S4: & RLCF & D4: & $A B J$ & 8488 & 58.00 & 492304.00 \\
\hline
\end{tabular}

\subsection{Sensitivity Analysis}

Tables 4.4 and 4.5 shows sensitivity analysis carried out on the problem parameters to see its effect on the optimal solution.

Table 4.4 Sensitivity Analysis Result on Constraints.

\begin{tabular}{llll}
\hline Constraints & Lower Limit & Current Value & Upper Limit \\
\hline 1 & 1327.00 & 1327.00 & 1327.00 \\
2 & 20110.00 & 20614.00 & 20614.00 \\
3 & 29205.00 & 46269.00 & Infinity \\
4 & - & 15433.00 & Infinity \\
5 & 18290.00 & 18290.00 & 18290.00 \\
6 & 13077.00 & 13077.00 & 13077.00 \\
7 & 12699.00 & 12699.00 & 12699.00 \\
8 & 8488.00 & 8488.00 & 8488.00 \\
9 & 1656.00 & 1656.00 & 1656.00 \\
10 & 1703.00 & 1703.00 & 1703.00 \\
11 & 3175.00 & 3175.00 & 3175.00 \\
12 & 7496.00 & 7496.00 & 7996.00 \\
13 & - & 17059.00 & - \\
\hline
\end{tabular}


Table 4.5 Sensitivity Analysis Result on Objective Function Variables.

\begin{tabular}{|c|c|c|c|}
\hline Variable & Lower Limit & Current Value & Upper Limit \\
\hline$X_{11}$ & 23.00 & 23.00 & 23.00 \\
\hline $\mathbf{X}_{12}$ & 23.00 & 23.00 & 23.00 \\
\hline$X_{13}$ & 23.00 & 23.00 & 23.00 \\
\hline$X_{14}$ & 23.00 & 23.00 & 23.00 \\
\hline$X_{15}$ & 47.00 & 53.00 & 53.00 \\
\hline$X_{16}$ & 47.00 & 53.00 & 53.00 \\
\hline $\mathbf{X}_{17}$ & 47.00 & 53.00 & 53.00 \\
\hline$X_{18}$ & 53.00 & 60.00 & 60.00 \\
\hline$X_{19}$ & - & 0.00 & - \\
\hline$x_{21}$ & 20.00 & 20.00 & 20.00 \\
\hline$x_{22}$ & 20.00 & 20.00 & 20.00 \\
\hline$X_{23}$ & 20.00 & 20.00 & 20.00 \\
\hline$X_{24}$ & 20.00 & 20.00 & 20.00 \\
\hline$X_{25}$ & 45.00 & 45.00 & 45.00 \\
\hline$X_{26}$ & 45.00 & 45.00 & 45.00 \\
\hline$X_{27}$ & 45.20 & 45.00 & 45.00 \\
\hline$X_{28}$ & 51.00 & 51.00 & 51.00 \\
\hline$X_{29}$ & - & 0.00 & - \\
\hline$x_{31}$ & 58.00 & 58.00 & 58.00 \\
\hline$x_{32}$ & 58.00 & 58.00 & 58.00 \\
\hline $\mathbf{X}_{33}$ & 58.00 & 58.00 & 58.00 \\
\hline$x_{34}$ & 58.00 & 58.00 & 58.00 \\
\hline$X_{35}$ & 82.00 & 133.00 & 133.00 \\
\hline$x_{36}$ & 82.00 & 133.00 & 133.00 \\
\hline$X_{37}$ & 82.00 & 133.00 & 133.00 \\
\hline$x_{38}$ & 88.00 & 150.00 & 150.00 \\
\hline$X_{39}$ & - & 0.00 & - \\
\hline$x_{41}$ & 58.00 & 58.00 & 58.00 \\
\hline$X_{42}$ & 58.00 & 58.00 & 58.00 \\
\hline$X_{43}$ & 58.00 & 58.00 & 58.00 \\
\hline$X_{44}$ & 58.00 & 58.00 & 58.00 \\
\hline$X_{45}$ & 82.00 & 133.00 & 133.00 \\
\hline$X_{46}$ & 82.00 & 133.00 & 133.00 \\
\hline$X_{47}$ & 82.00 & 133.00 & 133.00 \\
\hline$X_{48}$ & 88.00 & 159.00 & 159.00 \\
\hline$X_{49}$ & - & 0.00 & - \\
\hline
\end{tabular}




\section{Conclusion}

The transportation cost of goods in any company or organization is a pivotal element in determining the total cost of production and also the net profit that will be made.

In this study, an attempt was made to obtain a reduced transportation cost for some selected goods (Brabusco Maize Flour, Grand Pure Soya Oil, Vita Chicks Pelletized and Royal Layer Concentrate Feeds) produced at Grand Cereals Limited, Jos which were transported to the selected major distributors located in Yola, Dutse, Minna, Abuja, Aba, Onitsha, Calabar and Ikeja. Also Sensitivity Analysis was carried out to see how sensitive the transportation model solution will turn out to be.

From the result of the Vogel's Approximation Method used to obtain a reduced cost and the sensitivity analysis carried out, the following specific conclusions were drawn.

i. The transportation model (VAM) used was able to minimize the transportation cost of the products from $\mathrm{N} 3,760,000.00$ to $\mathrm{N} 3,427,821.00$ monthly.

ii. The company will save N332,179.00 monthly (N3,986,148.00 per annum) for the selected products and its transportation if the model is adopted.

iii. The optimal solution or reduced cost is strongly sensitive to changes from the problem parameters.

\section{Recommendations}

The following are the recommendations arising from this work.

i. The Management of Grand Cereals
Limited, Jos, should adopt the proposed transportation model, to help them plan their transportation schedule at a reduced cost.

ii. Based on the fact that Statistical Packages are necessary tools when it comes to decision making, the Management of Grand Cereals Limited, Jos, should introduce or adopt the use of these packages in their operations, not only in the transportation area, but also in the areas of production and administration.

\section{Reference}

Asase, A. (2011). "The Transportation Problem: A Case Study of Guinness Ghana Limited. M. Sc Thesis submitted to Kwame Nkurumah University of Science and Technology, Kumasi, Ghana.

Jonnson, P. (2008) "Logistic and Supply Chain Management". McGraw Hill Education.

Sen, N., Som, T. and Sinha, B. (2010). “A Study of Transportation Problem for an Essential Item of Southern Part of North Eastern Region of India as an OR Model and Use of Object Oriented Programming". IJCSNC, 10(5).

Sharma, S.D. (2010). "Operations Research", Keda Nath Ram Nath Publishers. Fifteenth Edition, India. Pp 262 